J Pediatr. 2009 September ; 155(3): 398-403. doi:10.1016/j.jpeds.2009.04.004.

\title{
ASTHMA AND SOCIAL ANXIETY IN ADOLESCENTS
}

\author{
Jean-Marie Bruzzese, Ph.D., \\ Department of Child and Adolescent Psychiatry, NYU School of Medicine, 215 Lexington Avenue, \\ $13^{\text {th }}$ Floor, New York, NY 10016
}

Paige H. Fisher, Ph.D., Department of Psychology, Seton Hall University

Nadia Lemp, M.A., and Graduate School of Applied \& Professional Psychology, Rutgers, The State University of New Jersey

Carrie Masia Warner, Ph.D. Department of Child and Adolescent Psychiatry, NYU School of Medicine and Nathan Kline Institute for Psychiatric Research, Orangeburg, NY

\section{Abstract}

Objective-To examine the relationship between self-reported social anxiety and asthma in a non-clinical sample of adolescents.

Study design-High school students ( $\mathrm{n}=765)$ completed the Social Anxiety Scale for Adolescents (SAS-A), the Social Phobia and Anxiety Inventory for Children (SPAI-C) and questions regarding asthma diagnosis, asthma symptoms and asthma-related limitations and medical care. Relationships were examined between social anxiety symptoms and asthma, including history of diagnosis, diagnosis plus current symptoms and severity.

Results-Compared with students without an asthma diagnosis and no symptoms, students with a diagnosis and current symptoms reported heightened social anxiety symptoms related to fear of negative evaluations and generalized discomfort in social settings as measured by the SAS-A. Additionally, a greater proportion of those with an asthma diagnosis and current symptoms were in the clinical range of social anxiety on the SAS-A. Differences on the SAS-A by history of asthma diagnosis and by severity were not supported. No differences were found on the SPAI-C for history of asthma diagnosis, diagnosis plus current symptoms or severity.

Conclusions-Students with current asthma symptoms are more likely to report social anxiety, perhaps related to concerns about exhibiting symptoms or taking medication in front of peers. These findings may suggest advantages for medical providers to identify and treat social anxiety in patients with asthma.

(C) 2009 Mosby, Inc. All rights reserved.

[CORRESPONDING AUTHOR]: PHONE: 212.263.3667, FAX: 212.263.3691, Jean-Marie.Bruzzese @ nyumc.org.

Publisher's Disclaimer: This is a PDF file of an unedited manuscript that has been accepted for publication. As a service to our customers we are providing this early version of the manuscript. The manuscript will undergo copyediting, typesetting, and review of the resulting proof before it is published in its final citable form. Please note that during the production process errors may be discovered which could affect the content, and all legal disclaimers that apply to the journal pertain.

C. M. W. received funding from NIMH (5K23MH065373). J.-M. B. received partial funding from NHLBI (R01HL079953) for the preparation of this manuscript. There is no potential, perceived or real conflict of interest for any of the authors. The sponsor played no role in (1) the study design; (2) the collection, analysis and interpretation of data; (3) the writing of the report; and (4) the decision to submit the manuscript. 


\section{Keywords}

adolescence; school-based; psychology; chronic disease

Asthma is the most common chronic illness in youth, with prevalence and morbidity that is higher in adolescents than in younger children. ${ }^{1}$ In youth, anxiety is associated with more asthma symptoms $\mathrm{s}^{2,3}$ and poorer adherence to daily monitoring of asthma symptoms. ${ }^{4}$ Social Anxiety Disorder (SAD), one of the most common anxiety disorders in adolescents, is characterized by intense fear of social or performance situations coupled with distress or avoidance that leads to significant impairment ${ }^{5}$ (e.g., few friends, loneliness, depressed mood, disturbances in school performance, and difficulty with interpersonal relationships). SAD may be particularly disabling during adolescence because peers play a critical role in social and identity development during this period. ${ }^{6}$

Adolescents with asthma may be especially at-risk for social anxiety. These youth report feeling different and isolated from their peers, ${ }^{7-10}$ fear peer rejection ${ }^{10}$ and have poor social competence. ${ }^{11}$ Moreover, their ability to identify with peers may be hampered if asthma leads to impairment in physical or social activities, such as sports and dance, ${ }^{12,13}$ thereby reducing the opportunity for social interactions. This isolation can be heightened if adolescents then purposefully avoid performance and social activities due to embarrassment about having attacks in front of peers. Additionally, due to adolescents' concern with peer acceptance, social anxiety may decrease compliance with treatment regimens that require taking medication in front of peers (e.g., taking quick-reliever medication prior to exercise or exposure to other triggers). ${ }^{12}$

Despite the potentially serious implications of the association between asthma and social anxiety in adolescents, few studies have considered this relationship. In this report, we explore the relationship between self-reported social anxiety and asthma in a community sample of high school students. We hypothesize that, compared with peers without asthma, adolescents with a diagnosis of asthma and current symptoms will report more symptoms of social anxiety. Furthermore, we predict that among adolescents diagnosed with asthma, those with more severe asthma will report more social anxiety.

\section{METHOD}

Participants were 765 adolescents from two urban, Catholic high schools. Their mean age was $15.2(\mathrm{SD}=.79) ; 76.9 \%$ were female. The majority were Caucasian $(87.0 \%)$. The grade distribution was $33.6 \%$ ninth graders, $48.3 \%$ tenth graders, and $18.1 \%$ eleventh graders. Data were obtained as part of a school-wide social anxiety screening for a controlled trial evaluating the efficacy of a cognitive-behavioral intervention for high school students with social anxiety disorder. ${ }^{14}$ Procedures were approved by the NYU School of Medicine Institutional Review Board.

\section{Measures}

Social Anxiety-The Social Anxiety Scale for Adolescents (SAS-A) ${ }^{15}$ assesses social fears in youth ages 12 to 18. Eighteen items, each on a 5-point Likert scale, are used to calculate a total score and three subscales: (1) Fear of Negative Evaluation (FNE); (2) Social Avoidance and Distress in New Situations (SAD-New); and (3) Social Avoidance and Distress in General Situations (SAD-General). The measure has adequate internal consistency, test-retest reliability and discriminate validity. ${ }^{16,17}$ Total scores greater than 50 indicate clinically significant social phobia. ${ }^{18}$ 
The Social Phobia and Anxiety Inventory for Children (SPAI-C) ${ }^{19,} 20$ contains 26 items on a 3-point Likert scale that assess specific somatic symptoms, cognition, and behavior across potentially fear-inducing situations. Initially developed for 8 to 13 year-olds, we adapted it for adolescents. Items mirror the diagnostic criteria for social phobia; total scores of 18 or greater indicate youth may fall in the clinical range of social phobia. The SPAI-C has been shown to be internally consistent and to have adequate test-retest reliability. ${ }^{19,} 20$ This measure has demonstrated sensitivity and specificity for social anxiety diagnosis. ${ }^{20-22}$

Asthma Questionnaire-Students completed 12 questions that ask: (1) if they were ever diagnosed with asthma; (2) frequency in the last 12 months of (a) symptoms (i.e., wheeze, shortness of breath/chest tightness, cough without a cold, and night wakening), (b) hospitalizations, (c) urgent or emergency visits to a doctor or hospital, (d) school asthmarelated absences and (e) physical and social activity asthma-related limitations; and (3) if they ever had wheeze severe enough to limit speech. Questions 2a through 2e have been used by the first author in several studies to identify adolescents with asthma. ${ }^{13,23}$ Question 3 is part of the ISAAC questionnaire, a standardized survey which has been used worldwide with adolescents ages 13 to 14 . We set this symptom threshold to rule out very mild intermittent asthma and to rule out cough and shortness of breath as the only presenting asthma symptoms. Cough alone was ruled out because cough is often misinterpreted in patients with asthma, and shortness of breath alone was ruled out because of it overlaps with anxiety symptoms.

Based on responses on the asthma questionnaire, we classified students into groups based on diagnosis and current symptoms. First, students were classified as having an asthma diagnosis (yes/no) if they reported they were ever diagnosed with asthma. Next, they were classified as having current symptoms if they reported 2 of 4 asthma symptoms with both symptoms occurring 3 or more days a month or reported 3 of 4 symptoms with at least 1 symptom occurring 3 or more days a month ${ }^{1}$. We placed students into one of two categories: (1) asthma diagnosis and current symptoms (i.e., current asthma) and (2) no asthma diagnosis and no current symptoms (i.e., no asthma). Students with an asthma diagnosis and no symptoms (i.e., well controlled or remittent asthma) and those without an asthma diagnosis and current symptoms (i.e., possible undiagnosed asthma) were excluded from current analyses.

Among those diagnosed with asthma, we next represented asthma severity three ways: (1) symptom frequency; (2) morbidity; and (3) functioning. Symptom frequency severity was operationally defined by (a) $\mathrm{NHLBI}^{24}$ criteria for mild intermittent, mild persistent, and moderate or severe persistent asthma and (b) if the student reported wheeze severe enough to limit speech in the last 12 months. Morbidity was defined as (a) making an urgent visit to a doctor or emergency room and (b) being hospitalized for asthma in the last 12 months. Functional severity was assessed by (a) the frequency of restrictions in activity and (b) the number of school absences in the last 12 months.

\section{Statistical Analyses}

For hypotheses comparing groups of students (e.g., diagnosis yes/no) on quantitative outcomes, such as total SAS-A and SPAI-C scores, we used independent sample $t$ tests or Analysis of Variance (ANOVA). For hypotheses involving binary outcomes, such as presence of clinically significant social anxiety, we used Pearson chi-square tests.

We also explored whether the size of the group difference on SAS-A and SPAI-C scores varied with age or sex by testing interactions of these variables with the asthma group variable. Because age is quantitative, we used linear regression to test these interactions. For sex, linear regression yields exactly the same interaction test as a two-way ANOVA. 
Effect sizes were computed using the Glass index because the Glass index is more precise than Cohen $d$ or Hedges $d$ ' for large sample sizes $(\mathrm{N}>300) .{ }^{25}$ A Glass index of .2 indicates a small effect size, .5 medium and .8 large.

\section{RESULTS}

\section{Descriptive Statistics}

Social Anxiety-SAS-A total scores ranged from 18 to 90 with a mean of 37.3 (SD=11.9). SPAI-C total scores ranged from 0 to 44 with a mean of 11.0 (SD=7.6). Overall, 13.7\% and $15.6 \%$ of the sample reported clinically significant social anxiety on the SAS-A and SPAI$\mathrm{C}$, respectively, as indicated by the recommended cutoffs (50 for SAS-A and 18 for SPAIC).

Asthma Diagnosis and Severity-Having an asthma diagnosis was reported by $18.6 \%$ of the sample, and $11.2 \%$ of the sample had current asthma (i.e., a diagnosis and current symptoms). Applying NHLBI ${ }^{24}$ criteria, $31.4 \%$ of those with current asthma had mild intermittent asthma, $36.1 \%$ mild persistent, $24.4 \%$ moderate persistent, and $8.1 \%$ severe persistent. Over the last year, among those with current asthma, 20.9\% reported wheeze severe enough to limit speech, $43.0 \%$ made an urgent visit to a doctor or emergency room and $9.3 \%$ were hospitalized for asthma. With respect to functional morbidity, $80.2 \%$ of those with current asthma reported having physical or social limitations and $61.6 \%$ were absent from school.

\section{Differences in Social Anxiety by Asthma Diagnosis}

Table I presents means, standard deviations and test statistic details for social anxiety scores by asthma diagnosis. No significant differences were found on the SAS-A or SPAI-C by asthma diagnosis. Additionally, there were no differences in the proportion of students with asthma who fell in the clinical range of social anxiety on the SAS-A compared with those with no asthma ( $15.5 \%$ and $13.3 \%$, respectively; $\left.X_{(1)}^{2}=.50\right)$ and the SPAI-C (12.6\% and $16.3 \%$, respectively; $\left.X_{(1)}^{2}=.27\right)$.

\section{Differences in Social Anxiety by Asthma Diagnosis with Current Symptoms.}

Table I shows the means, standard deviations and test statistic details for social anxiety for those with an asthma diagnosis with current symptoms and those with no asthma. The means, standard deviations and test statistic details for SAS-A subscales are presented in Table II. Diagnosed students with current symptoms reported significantly greater total social anxiety scores on the SAS-A than undiagnosed peers with no symptoms. Significant main effects were found for two of the three SAS-A subscales: negative evaluation and social anxiety in generalized situations. No significant differences were found on the SPAI$\mathrm{C}$ between those diagnosed with current symptoms and those with no asthma. There was also no evidence that asthma group interacted with age or sex in its association with SAS-A or SPAI-C ( $p$ value for each of these interactions was greater than .78).

A significantly greater proportion of students with an asthma diagnosis and current symptoms fell in the clinical range of social anxiety than asymptomatic, undiagnosed students $\left(20.9 \%\right.$ and $12.8 \%$, respectively; $\left.X^{2}{ }_{(1)}=4.0, p<.05\right)$ on the SAS-A. No significant differences were found for the SPAI-C $\left(X^{2}{ }_{(1)}=.94\right)$ with $15.1 \%$ of those with current asthma falling in the clinical range versus $14.8 \%$ of those with no asthma. 


\section{Social Anxiety Differences by Asthma Severity}

Table III presents the means and standard deviations for social anxiety for those with current asthma by asthma severity. Among those with current asthma, social anxiety did not differ by asthma severity.

\section{DISCUSSION}

We examined the relation between social anxiety and asthma in adolescents. Consistent with results from a community sample that found no relationship between a history of asthma attacks and social phobia, ${ }^{26}$ we found no differences in reports of social anxiety by asthma diagnosis. However, those with current asthma (i.e., a diagnosis and current asthma symptoms) endorsed higher levels of social anxiety on the SAS-A than peers without asthma. More specifically, teenagers with an asthma diagnosis and current symptoms feared being viewed negatively by their peers and reported more generalized discomfort or inhibition in social situations than their counterparts without asthma. However, they did not fear new situations or unfamiliar peers more so than those without asthma. Moreover, compared with students without asthma, a greater proportion of symptomatic, diagnosed students were in the clinical range of social anxiety on the SAS-A.

Together, these findings suggest that current asthma symptoms, rather than a history of asthma, may be more relevant to social anxiety. Experiencing asthma symptoms may be accompanied by appearing visibly distressed or taking medication in front of friends, which may elevate fears associated with social evaluation. Adolescents often express fear and embarrassment regarding asthma and taking medication in front of peers. ${ }^{27,} 28$ They report being teased, fearing peer rejection and feeling isolated because of their illness, $7,9,10$ which may account for an increase in social anxiety, particularly fear of being negatively evaluated by peers and distress in social situations. This might also explain why students did not report elevated fears of new situations. That is, if their primary concerns correspond to being embarrassed in front of peers, they might be less anxious about asthma symptoms or taking medication in front of strangers with whom they do not have regular contact.

A fear of being negatively evaluated by peers may also impede adolescents from taking steps to prevent and manage asthma, such as taking quick-reliever medication before exercising or at symptoms onset. Conversely, fear of appearing different from peers when experiencing public asthma symptoms may increase motivation to manage asthma. ${ }^{13}$ Although we did not assess adolescents' steps to prevent and manage asthma symptoms, future studies might explore how social anxiety impacts asthma prevention and management. Future studies should also explore others factors that might mediate the relationship between asthma and social anxiety, such as how long the adolescent has been diagnosed with asthma, self-efficacy to control asthma, and social support from peers.

Another purpose of this study was to determine if asthma severity was related to social anxiety symptoms. The absence of such a relationship was unanticipated given the association with asthma severity and a variety of anxiety disorders and anxiety symptoms in past studies. ${ }^{2,3,29-32}$ For example, in a study of adolescents ages 11 to 17 with asthma in an HMO, youth with at least one anxiety disorder reported more days with asthma symptoms than those without an anxiety disorder, and youth with more anxiety symptoms had a higher asthma symptom burden. ${ }^{3}$ In this same sample, McCauley et al report that youth who endorsed more symptoms of anxiety also reported greater asthma-related functional impairment. ${ }^{29}$ Kean and colleagues found a relationship between asthma functional morbidity and anxiety symptoms among 12 - to 18 -year olds with asthma. ${ }^{32}$ Finally, in a meta-analysis of over 4,900 youth with asthma aged 4 to 19 , McQuaid et al ${ }^{30}$ concluded that internalizing problems increase with asthma severity. 
Specifically for social anxiety disorder, one study found a relationship between self-reported social anxiety and the severity of respiratory symptoms in Dutch children ages 11 to $16 .{ }^{33}$ However, similar to our results, Bender and colleagues ${ }^{34}$ found no relation between selfratings of social anxiety and asthma severity in over 1,000 children ages 5 to 12 with mild to moderate asthma from 8 clinical centers in North America. Discrepancies in social anxiety studies may be attributable to varying methodologies and populations. The Dutch study, conducted with a European sample, used a Dutch translation of the Spence Children's Anxiety Scale; the other two studies were conducted in North America and utilized the SAS.

Perhaps for general anxiety, the impact of intensified asthma symptoms may strengthen the relationship between severity and anxiety. In contrast, for social anxiety, the concern regarding peer evaluation may predominate, overriding the role of asthma symptom severity.

Our finding that adolescents with current asthma symptoms exhibit greater social anxiety when assessed by the SAS-A, but not the SPAI-C, may be due to the discrepant nature of these measures. Although similar, they do not assess identical constructs. ${ }^{35}$ The SAS-A measures general social anxiety or distress (e.g., I feel shy around people I don't know), and the SPAI-C assesses anxiety in a variety of specific social and performance situations (e.g., speaking in front of groups, attending parties, eating in the cafeteria, school performances), as well as cognitive, physiological, and behavioral correlates of social anxiety disorder (e.g., worry about making mistakes, headaches, and avoidance or social situations). Asthma symptoms may be related more to general social distress and anxiety as assessed by the SAS-A rather than the specific situations and experiences represented in the SPAI-C. Similarly, within the SAS-A subscales, we found a relationship with social anxiety in general and fear of negative evaluation, but not with novel situations or with new peers. Anxiety in new situations or with unfamiliar peers is common for those with social anxiety disorder.

One limitation of this study is that the sample was predominately white, middle to uppermiddle class students. Another is that all data were self-reported. It is possible that some adolescents do not recall receiving an asthma diagnosis or that their parents may not have shared this information with them. Furthermore, they may not accurately recall the frequency of their asthma symptoms or events surrounding asthma, such as school absences. Responses on the social anxiety measures may have also be influenced by social desirability. The data used in this report were collected as part of the screening procedures for a social anxiety intervention ${ }^{14}$ and were not anonymous. Some students may have responded to appear less socially anxious, consequently weakening any potential relationships.

We therefore recommend this study be replicated using an ethnically and socioeconomically diverse sample to increase generalization. Future studies should also confirm asthma diagnoses, asthma severity and social anxiety diagnoses using objective measures. The field would also benefit from comparisons with youth who are diagnosed but asymptomatic either because they no longer have asthma or because it is well controlled, and to youth who might have undiagnosed asthma.

The elevation in social anxiety among adolescents with current asthma may suggest the need for identification and treatment of social anxiety in patients with asthma. Increased collaboration with mental health experts may be necessary to train nurses and pediatricians to identify social anxiety disorder and to use this information to guide their treatment approach (e.g., linking asthma control to fitting in with peers and exploring potential barriers of medication use in front of others). Medical providers should consider referring the adolescent to a mental health professional for evaluation when social anxiety appears to interfere with disease management and exacerbate asthma. 


\section{Acknowledgments}

The authors would like to thank Dr. Patrick Shrout for his statistical consultation on this manuscript.

\section{REFERENCES}

1. ISAAC. Worldwide variations in the prevalence of asthma symptoms: the International Study of Asthma and Allergies in Childhood (ISAAC). Eur Respir J. 1998; 12:315-35. [PubMed: 9727780]

2. Bender BG, Zhang L. Negative affect, medication adherence, and asthma control in children. J Allergy Clin Immunol. 2008; 122:490-5. [PubMed: 18602153]

3. Richardson LP, Lozano P, Russo J, McCauley E, Bush T, Katon W. Asthma symptom burden: relationship to asthma severity and anxiety and depression symptoms. Pediatrics. 2006; 118:104251. [PubMed: 16950996]

4. Burkhart PV, Rayens MK. Self-concept and health locus of control: factors related to children's adherence to recommended asthma regimen. Pediatr Nurs. 2005; 31:404-9. [PubMed: 16295156]

5. American Psychiatric Association. Diagnostic and Statistical Manual of Mental Disorders -- IV. Author; Washington, DC: 1994.

6. Buhrmester D, Furman W. The development of companionship and intimacy. Child Dev. 1987; 58:1101-13. [PubMed: 3608659]

7. Kyngäs H. Support network of adolescents with chronic disease: adolescents' perspective. Nurs Health Sci. 2004; 6:287-93. [PubMed: 15507049]

8. Kyngäs HA, Kroll T, Duffy ME. Compliance in adolescents with chronic diseases: a review. J Adolesc Health. 2000; 26:379-88. [PubMed: 10822178]

9. Price JF. Issues in adolescent asthma: what are the needs? Thorax. 1996; 51(Suppl 1):S13-7. [PubMed: 8658384]

10. Fitzgerald D. Non-compliance in adolescents with chronic lung disease: causative factors and practical approach. Paediatr Respir Rev. 2001; 2:260-7. [PubMed: 12052328]

11. Vila G, Nollet-Clemencon C, de Blic J, Mouren-Simeoni MC, Scheinmann P. Prevalence of DSM IV anxiety and affective disorders in a pediatric population of asthmatic children and adolescents. J Affect Disord. 2000; 58:223-31. [PubMed: 10802131]

12. Randolph CC, Fraser B. Stressors and concerns in teen asthma. Allergy Asthma Proc. 1998; 19:193-203. [PubMed: 9727151]

13. Bruzzese J-M, Bonner S, Vincent EJ, Sheares BJ, Mellins RB, Levison MJ, et al. Asthma education: the adolescent experience. Patient Educ Couns. 2004; 55:396-406. [PubMed: 15582346]

14. Masia Warner C, Fisher PH, Shrout PE, Rathor S, Klein RG. Treating adolescents with social anxiety disorder in school: an attention control trial. J Child Psychol Psychiatry. 2007; 48:676-86. [PubMed: 17593148]

15. La Greca, AM. Social anxiety scales for children and adolescents: Manual and instructions for the SASC, SASC-R, SAS-A, and parent versions of the scales. 1998. Unpublished manuscript available from the author

16. Storch EA, Masia Warner C, Dent HC, Roberti JW, Fisher PH. Psychometric evaluation of the Social Anxiety Scale for Adolescents and the Social Phobia and Anxiety Inventory for Children: construct validity and normative data. J Anxiety Disord. 2004; 18:665-79. [PubMed: 15275945]

17. Ginsburg GS, La Greca AM, Silverman WK. Social anxiety in children with anxiety disorders: relation with social and emotional functioning. J Abnorm Child Psychol. 1998; 26:175-85. [PubMed: 9650624]

18. La Greca AM. The social anxiety scales for children and adolescents. Behav Ther. 1998; 22:133-6.

19. Beidel DC, Turner SM, Morris TL. A new inventory to assess childhood social anxiety and phobia: The Social Phobia and Anxiety Inventory for Children. Psychol Assess. 1995; 7:73-9.

20. Beidel DC, Fink CM, Turner SM. Stability of anxious symptomatology in children. J Abnorm Child Psychol. 1996; 24:257-69. [PubMed: 8836801] 
21. Inderbitzen-Nolan H, Davies CA, McKeon ND. Investigating the construct validity of the SPAI-C: comparing the sensitivity and specificity of the SPAI-C and the SAS-A. J Anxiety Disord. 2004; 18:547-60. [PubMed: 15149713]

22. Beidel DC, Turner SM, Hamlin K, Morris TL. The Social Phobia and Anxiety Inventory for Children (SPAI-C): external and discriminative validity. Behav Ther. 2000; 31:75-87.

23. Bruzzese J-M, Unikel LH, Gallagher R, Evans D, Colland VT. Feasibility and impact of a schoolbased intervention for families of urban adolescents with asthma: results from a randomized pilot trial. Fam Process. 2008; 47:95-113. [PubMed: 18411832]

24. N.H.L.B.I. Guidelines for the Diagnosis and Management of Asthma NIH Publication No. 97-4051. NIH; Bethesda: 1997.

25. Hess, B.; Olejnik, S. Revisiting the efficacy of Glass's estimator of effect size for program impact analysis; Annual Meeting of the American Educational Research Association; Seattle, WA. 2001;

26. Ortega AN, McQuaid EL, Canino G, Goodwin RD, Fritz GK. Comorbidity of asthma and anxiety and depression in Puerto Rican children. Psychosomatics. 2004; 45:93-9. [PubMed: 15016921]

27. Cohen R, Franco K, Motlow F, Reznik M, Ozuah P. Perceptions and attitudes of adolescents with asthma. J Asthma. 2003; 40:207-11. [PubMed: 12765323]

28. Gibson PG, Henry RL, Vimpani GV, Halliday J. Asthma knowledge, attitudes, and quality of life in adolescents. Arch Dis Child. 1995; 73:321-6. [PubMed: 7492196]

29. McCauley E, Katon W, Russo J, Richardson L, Lozano P. Impact of anxiety and depression on functional impairment in adolescents with asthma. Gen Hosp Psychiatry. 2007; 29:214-22. [PubMed: 17484938]

30. McQuaid EL, Kopel SJ, Nassau JH. Behavioral adjustment in children with asthma: a metaanalysis. J Dev Behav Pediatr. 2001; 22:430-9. [PubMed: 11773808]

31. Weil CM, Wade SL, Bauman LJ, Lynn H, Mitchell H, Lavigne J. The relationship between psychosocial factors and asthma morbidity in inner-city children with asthma. Pediatrics. 1999; 104:1274-80. [PubMed: 10585977]

32. Kean EM, Kelsay K, Wamboldt F, Wamboldt MZ, Kean EM, Kelsay K, et al. Posttraumatic stress in adolescents with asthma and their parents. J Am Acad Child Adolesc Psychiatry. 2006; 45:7886. [PubMed: 16327584]

33. Rietveld S, van Beest I, Prins PJM. The relationship between specific anxiety syndromes and somatic symptoms in adolescents with asthma and other chronic diseases. J Asthma. 2005; 42:725-30. [PubMed: 16316865]

34. Bender BG, Annett RD, Ikle D, DuHamel TR, Rand C, Strunk RC. Relationship between disease and psychological adaptation in children in the Childhood Asthma Management Program and their families. CAMP Research Group. Arch Pediatr Adolesc Med. 2000; 154:706-13. [PubMed: 10891023]

35. Morris TL, Masia CL. Psychometric evaluation of the social phobia and anxiety inventory for children: concurrent validity and normative data. J Clin Child Psychol. 1998; 27:452-8. [PubMed: 9866082] 


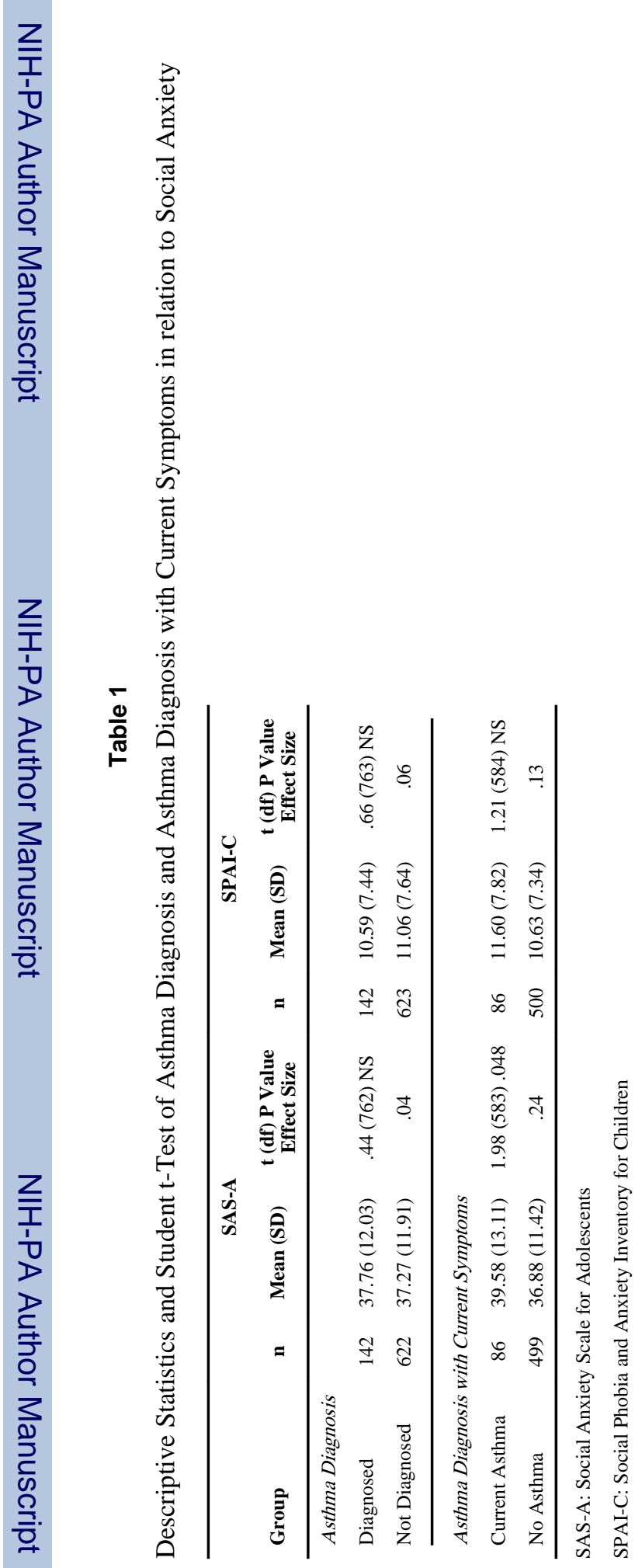

J Pediatr. Author manuscript; available in PMC 2013 May 23. 
造

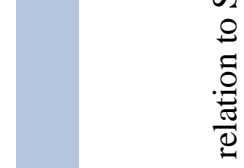

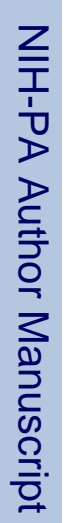

.

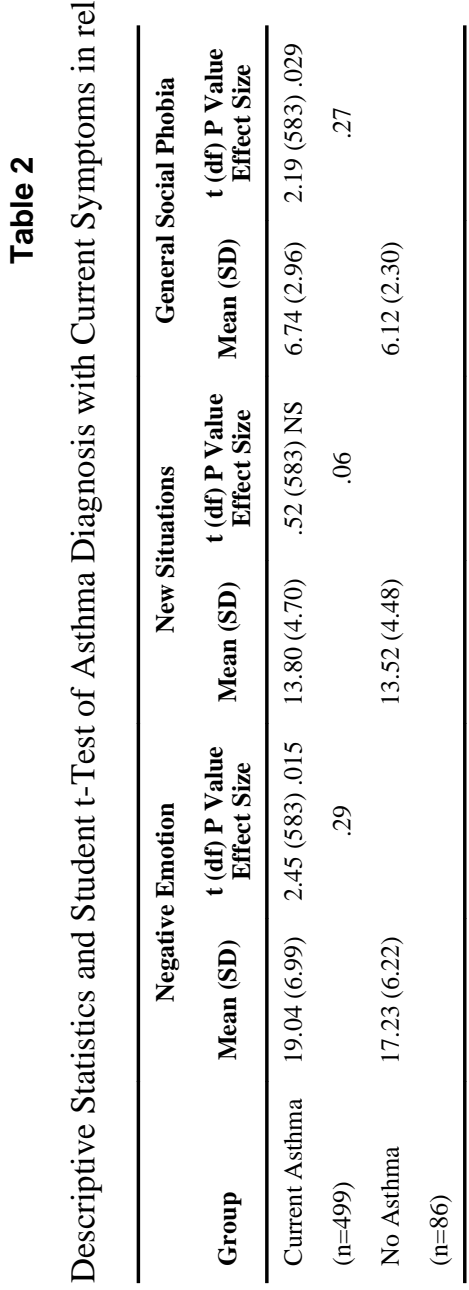

J Pediatr. Author manuscript; available in PMC 2013 May 23. 
Table 3

Mean and standard deviation for SPAI-C and SAS-A by Asthma Severity

\begin{tabular}{|c|c|c|c|c|}
\hline \multirow[b]{2}{*}{ Asthma Severity } & \multicolumn{2}{|c|}{ SAS-A } & \multicolumn{2}{|c|}{ SPAI-C } \\
\hline & Mean (SD) & $\begin{array}{l}\text { t (df) P Value } \\
\text { Effect Size }\end{array}$ & Mean (SD) & $\begin{array}{c}\text { t (df) P Value } \\
\text { Effect Size }\end{array}$ \\
\hline \multicolumn{5}{|c|}{ Symptom Severity } \\
\hline \multicolumn{5}{|l|}{ NHLBI Criteria } \\
\hline Mild Intermittent $(\mathrm{n}=27)$ & $34.48(11.71)$ & $.170(2,83) \mathrm{NS}^{a}$ & $11.48(6.21)$ & $.441(2,83) \mathrm{NS}$ \\
\hline Mild Persistent (n=31) & $40.52(13.64)$ & $.52^{b}, .44^{c}, .07^{d}$ & $10.73(8.63)$ & \\
\hline $\begin{array}{l}\text { Moderate or Severe } \\
\text { Persistent }(n=28)\end{array}$ & $39.61(14.26)$ & & $12.65(8.40)$ & \\
\hline \multicolumn{5}{|l|}{ Wheeze Limit Speech } \\
\hline No $(n=68)$ & $39.90(13.76)$ & $.442(84) \mathrm{NS}$ & $11.35(7.98)$ & $-.573(84) \mathrm{NS}$ \\
\hline Yes $(n=18)$ & $38.36(10.57)$ & .11 & $12.54(7.33)$ & .15 \\
\hline \multicolumn{5}{|c|}{ Morbidity } \\
\hline \multicolumn{5}{|l|}{ Urgent Visits } \\
\hline No $(n=49)$ & $39.65(12.82)$ & $.058(84) \mathrm{NS}$ & $10.71(6.80)$ & $-1.215(84) \mathrm{NS}$ \\
\hline Yes $(n=37)$ & $39.49(13.67)$ & .012 & $12.77(8.97)$ & .30 \\
\hline \multicolumn{5}{|l|}{ Hospitalized } \\
\hline No $(n=78)$ & $40.09(13.24)$ & 1.124 (84) NS & $11.54(8.14)$ & $-.184(84) \mathrm{NS}$ \\
\hline Yes $(n=8)$ & $34.63(4.03)$ & .42 & $12.08(3.59)$ & .07 \\
\hline \multicolumn{5}{|c|}{ Functional Severity } \\
\hline \multicolumn{5}{|l|}{ Physical or Social Restrictions } \\
\hline No $(n=16)$ & $42.31(14.84)$ & $.867(83) \mathrm{NS}$ & $11.02(6.49)$ & $-.311(83) \mathrm{NS}$ \\
\hline Yes $(n=69)$ & $39.16(12.70)$ & .21 & $11.70(8.18)$ & .11 \\
\hline \multicolumn{5}{|l|}{ School Absences } \\
\hline No $(n=33)$ & $38.12(12.02)$ & $-.813(84) \mathrm{NS}$ & $11.22(7.56)$ & $-.342(84) \mathrm{NS}$ \\
\hline Yes $(n=53)$ & 40.49 (13.78) & .20 & $11.82(8.04)$ & .08 \\
\hline
\end{tabular}

SAS-A: Social Anxiety Scale for Adolescents

SPAI-C: Social Phobia and Anxiety Inventory for Children

$\stackrel{a}{=}$ F statistic

$\stackrel{b}{=}$ mild intermittent versus mild persistent

$\stackrel{c}{=}$ mild intermittent versus moderate/severe persistent

$\stackrel{d}{=}$ mild persistent versus moderate/severe persistent 